\title{
Childhood location correlates with epigenetic age and methylation stability in British-Bangladeshi migrants
}

\author{
Reinhard Stöger ${ }^{*}$, Minseung Choi², Gregory Leeman ${ }^{1 \#, ~ R i c h a r d ~ D . ~ E m e s ~}{ }^{3,4}$, \\ Khurshida Begum ${ }^{5}$, Philippa Melamed 6 , Gillian R. Bentley ${ }^{5,7}$
}

E-Mail addresses: RS: reinhard.stoger@nottingham.ac.uk; MS: minseung@stanford.edu; GL gregoryleeman@outlook.com; RDE: richard.emes@nottingham.ac.uk; KB: khurshida.begum@qmul.ac.uk; PM: philippa@tx.technion.ac.il; GRB: g.r.bentley@durham.ac.uk

*Corresponding author: Reinhard Stöger, E-mail: reinhard.stoger@nottingham.ac.uk 


\section{Abstract}

\section{Background}

3 Migration from one environment to another often causes marked changes in developmental conditions. Here we compare epigenetic ageing and stability of the epigenetic maintenance system among British-Bangladeshi women who grew up in Bangladesh (adult migrants), where there are higher pathogen loads and poorer health care, to second-generation Bangladeshis who grew up in the UK. In our previous studies of these migrants, those who spent their childhoods in Bangladesh also had lower levels of reproductive hormones and a shorter reproductive lifespan compared to those who grew up in the UK, suggesting life history trade-offs during development. In the present study, we hypothesised that women who grew up in Bangladesh would have $I$ ) an older epigenetic/biological age compared to the women with a childhood in the UK and ii) that differences in the pace of epigenetic ageing might also be reflected by altered stability of DNA methylation marks.

\section{Results}

Illumina EPIC array methylation data from buccal tissue was used to establish epigenetic age estimates from 15 adult migrants and 11 second-generation migrants, aged 18-35 years. Using residuals from linear regression of DNA methylation-based biological age (DNAm age) on the chronological age, the results showed significant differences $(p=0.016)$ in epigenetic age estimates: women whose childhood was in Bangladesh are on average 6.02 ( \pm 2.34 ) years older, than those who grew up in London. We further investigated the efficiency of the epigenetic maintenance system which purportedly is reflected by epigenetic clocks. Methylation states of CpGs at the LHCGR/LHR locus, which contributes to Horvath's multi tissue epigenetic clock were evaluated. Based on the Ratio of Concordance Preference (RCP) approach that uses double-stranded methylation data, we find that maintenance of epigenetic information is more stable in women who grew up in Bangladesh.

\section{Conclusions}

The work supports earlier findings that adverse childhood environments lead to phenotypic life history trade-offs. The data indicate that childhood environments can induce subtle changes to the epigenetic maintenance system that are detectable long after exposure occurred. The implication of such a finding warrants further investigation as it implies that a less flexible epigenetic memory system established early in life could reduce the capacity to respond to different environmental conditions in adult life.

\section{Keywords}

34 Childhood, migrants, epigenetic age, RCP values, epigenetic stability, DNA methylation, accelerated ageing, Bangladesh, UK. 


\section{Background}

38 Reproductive lifespans vary among individuals. Genetic variants associated with these complex traits, which include timing of puberty, age at first birth and age at menopause are closely related to fitness and undergo purifying selection $[1,2]$. The genetic architecture of reproductive ageing has been investigated largely in women of European ancestry. However, a limited number of studies in other populations suggests shared genetic underpinnings of these reproductive phenotypes, albeit with noticeable variations in effect allele frequencies and effect estimates in women of different ethnic groups [3-5]. Environmental exposures likely contribute to variations in heritability estimates and the phenotypic heterogeneity detected within and across different ethnic populations $[6,7]$.

Our earlier work identified strong correlations between childhood environmental conditions and adult reproductive function [8-10]. In particular, Bangladeshi women who migrated as young adults to London, have lower levels of reproductive steroids when compared to British-Bangladeshi women who moved to the UK prior to the age of eight and women who were born in London to first-generation Bangladeshi immigrants [7,9-11]. An upbringing in

Bangladesh is generally associated with a shortened reproductive lifespan, while its duration is longer for women with Bangladeshi ancestry, whose childhoods were spent in London [9]. Timing of reproductive functions across the life course correlates with the rate of ageing in other body systems [12].

Geographically and culturally the British-Bangladeshis women in these studies have a comparable background. They are all ethnic Bengalis and originally stem from a relatively affluent middle-class population in the northeast of Bangladesh and now live in East London. A possible environmental factor that distinguishes between the two childhood locations is the exposure to higher and recurrent infectious disease loads in Bangladesh [13-15]. Indeed, by mimicking early-life immune challenges in a mouse model, we replicated some of the distinct reproductive phenotypes characteristic of women with a childhood in Bangladesh, in including delayed onset of puberty lower ovarian reserve [16].

At the cellular level, environmental factors influence the chromatin state of the genome [17]. Stored as epigenetic information, cells have the capacity to retain some memory of past developmental and environmental conditions [18]. Methylation of genomic DNA is part of the epigenetic information storage system in mammalian cells where it is primarily confined to cytosines of $\mathrm{CpG}$ dinucleotides [19]. Methylation levels of discrete CpG sites have been 
used to develop remarkably accurate estimators of age. Such 'epigenetic clocks' link developmental and maintenance processes to biological ageing [reviewed in [20]]. Pace of ageing can vary and result in a mismatch between chronological and biological age of an individual [21].

Here, we explore the possible association between chronological age, biological ageing and an epigenetic maintenance system in Bangladeshi women of prime reproductive age (18-35 years old). The women of this study live within the same ethnic community in London but can be divided into two groups: those with a childhood in the UK, and those with a childhood in Sylhet, a city in the northeast region of Bangladesh. Using buccal cell DNA from these London-based Bangladeshi women, we recently identified genome-wide, altered DNA methylation levels between the two groups [16]. Since these DNA methylation measurements were generated on the MethylationEpic array platform, we re-examined the data using 'Horvath's clock', a multi-tissue age-estimator with a robust relationship between chronological age and DNA methylation-based (DNAm) age [22].

\section{Results and Discussion}

\section{Accelerated DNAm Age measured with Horvath's epigenetic clock}

We find that the correlation between chronological age and DNAm age does not differ significantly between women who grew up the UK ('UK' group; $n=11$ ) and women who grew up in Bangladesh ('Bangladesh' group; $n=15$ ). That is, chronological age affects DNAm age in a similar way in both groups (Additional file 1). However, regression analysis showed that the $y$-intercepts of the UK and Bangladeshi groups differ significantly $(p=0.0083)$ / Additional file 1). This suggested that a childhood in Bangladesh correlates with DNAm Age predictions that differ noticeable when compared with epigenetic age estimates for women of the UK group.

The tick rate of epigenetic clocks is increased by many different environmental factors, including psychological traumas, smoking, asthma, alcohol, infections and hormonal changes following menopause [23-26]. Such acceleration of epigenetic age is best measured by residuals obtained from regressing DNAm age on chronological age [22]. Indeed, the pace of epigenetic ageing is accelerated in women with a childhood in

103 Bangladesh and overall differs significantly from the UK group $(p=0.016)$ (Figure 1). This

104 altered pace of biological ageing is consistent with our previous observations that women who grow up in Bangladesh have a shorter reproductive lifespan and chronically lower levels of reproductive hormones $[9,13,15]$; reviewed in [7]. Although our finding of accelerated 
epigenetic ageing rests on a small number of sampled individuals, it highlights the limited utility of epigenetic clocks as a tool to determine the age - and consequently eligibility considerations - of asylum-seekers [27].

110

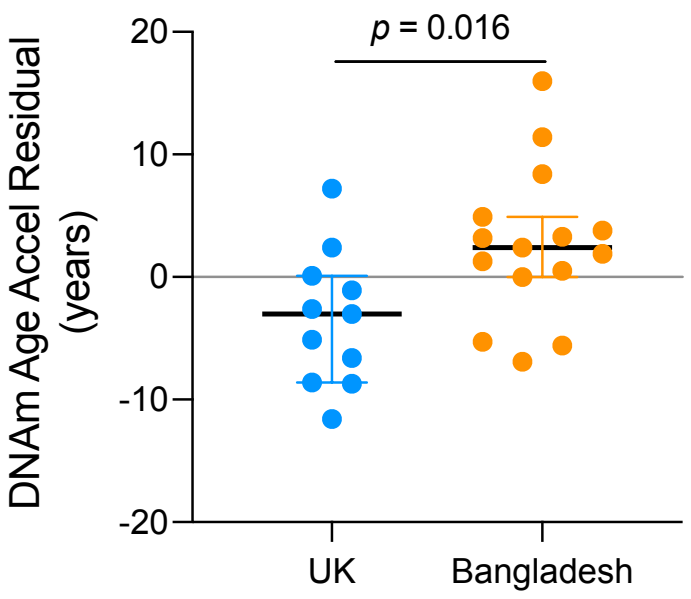

Childhood

Fig. 1 Differences in pace of epigenetic ageing

114 Plot of DNAm Age Accel Residuals, with each data point representing an individual. The colour indicates the corresponding dataset: blue $=$ childhood in UK, orange $=$ childhood in Bangladesh. The median is indicated by a horizontal line with upper and lower hinges representing the 25th and 75th percentiles. A positive or negative value indicates that the estimated epigenetic/biological age of the sample is higher or lower, respectively, than expected based on chronological age.

\section{Epigenetic stability of a clock locus}

122 The tick rate of Horvath's epigenetic clock is thought to reflect the rate at which work is done

123 to maintain epigenetic stability $[20,22]$. It is possible to infer epigenetic stability by analysing

124 double-stranded DNA methylation data with a new metric, Ratio of Concordance Preference

125 (RCP) [28]. We used the RCP metric to estimate epigenetic stability at the Luteinizing

126 Hormone/Choriogonadotropin Receptor (LHCGR/LHR) gene, which plays an important role

127 in reproductive function. The LHCGR locus contains a CpG site, which contributes to

128 Horvath's DNAm Age clock [22].

129 We find that RCP estimates are generally higher for the 'Bangladeshi' group of women

130 (Figure 2). Higher RCP estimates indicate higher levels of epigenetic stability [28]. That is,

131 the methylation states of CpGs at LHCGR locus are more often identical on the two strands 
132 of individual DNA molecules of 'Bangladeshi' individuals when compared to 'UK' individuals.

133 We note that the RCP estimates are based on a relatively small number of data points

134 (Additional file 1), yet they are sufficient to indicate subtle differences in the workings of the

135 epigenetic maintenance system between two groups of women who appear to age at

136 different rates.

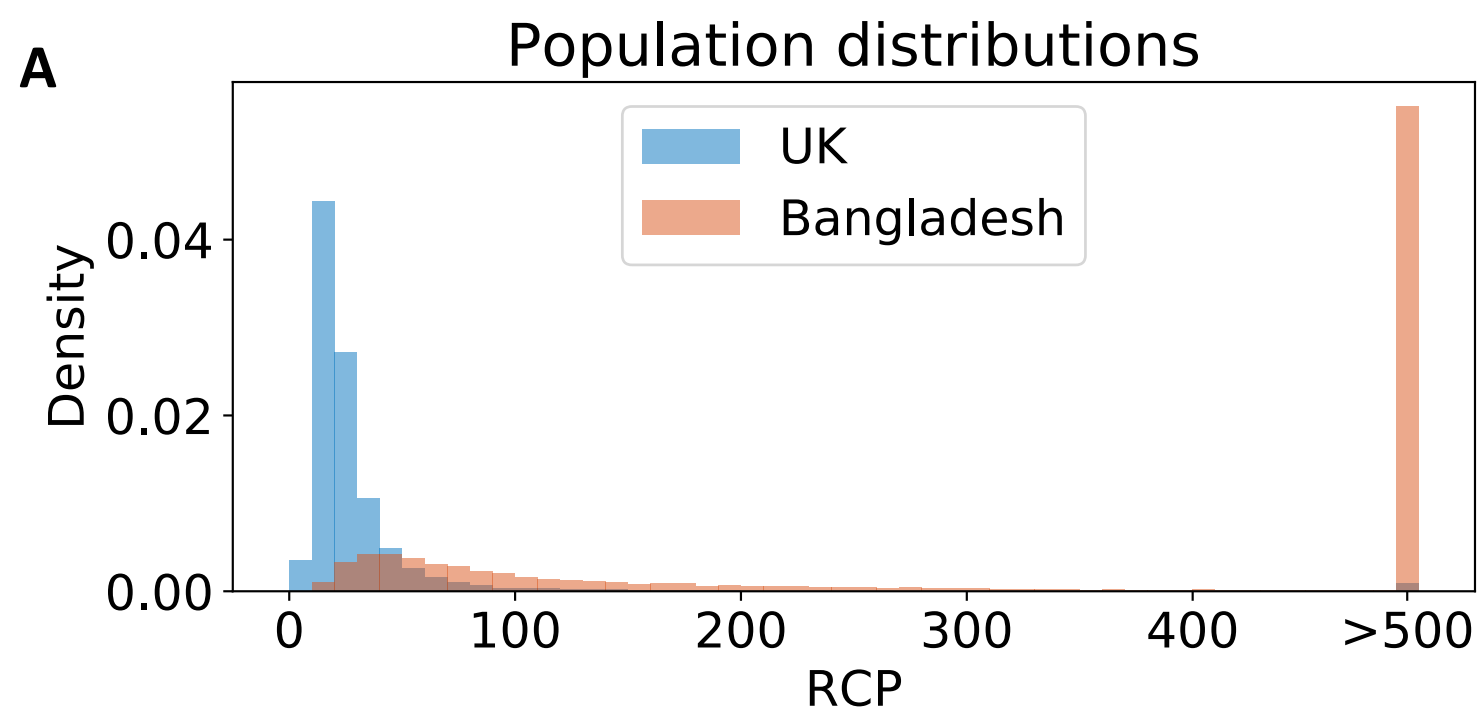

B Difference

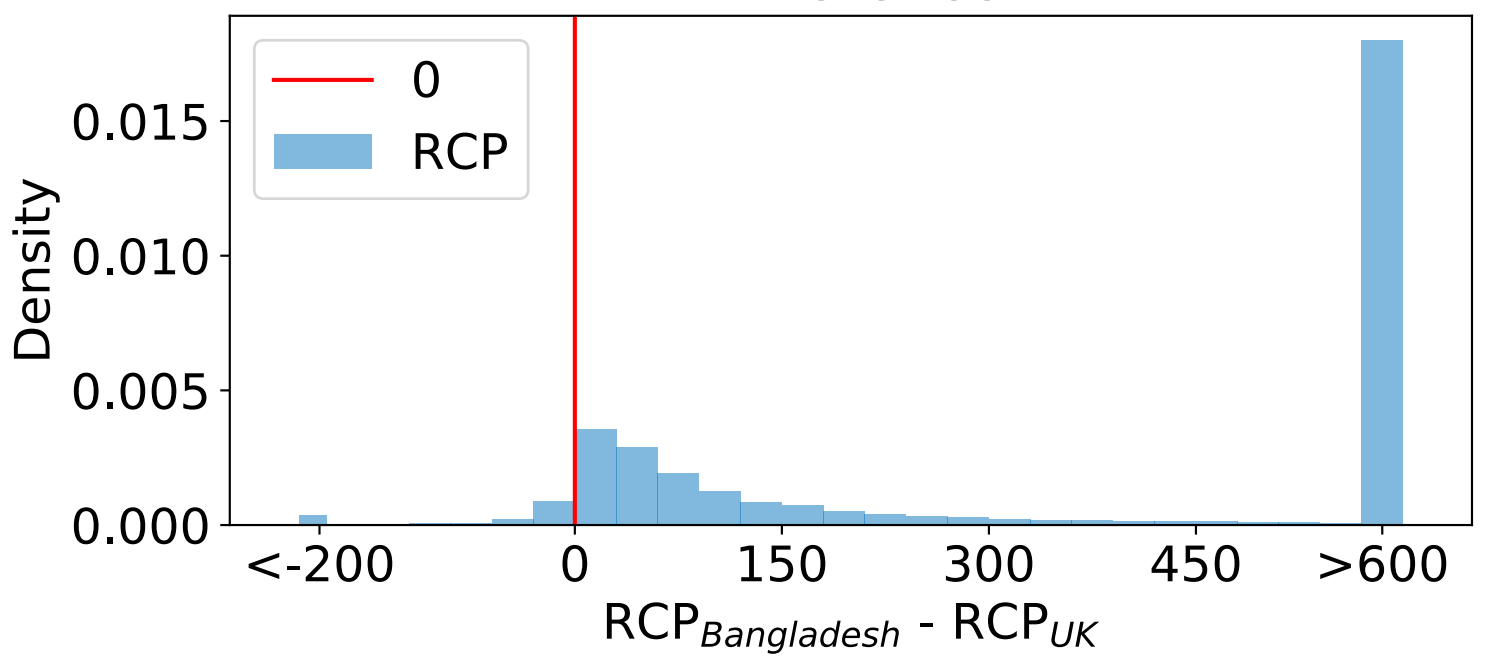

Fig. 2 Inferences of DNA methylation stability differ between UK and Bangladeshi samples at the epigenetic-clock associated LHCGR/LHR locus.

A) Ratio of Concordance Preference $(\mathrm{RCP})$ is a metric that infers stability/flexibility of methylation states at matching $\mathrm{CpG}$ sites (CpG dyads) on the parent and daughter strand of individual DNA molecules, without assuming any specific enzymatic mechanisms of DNA methylation. Flexibility, indicated by RCP values near 1, indicates that the methylation system has no preference for either concordance or discordance of the methylation state at 
a CpG dyad and follows the random model. High RCP values - with the extreme approaching infinity - indicate high stability, where epigenetic maintenance systems have complete preference for concordant methylation states of $\mathrm{CpG}$ dyads (they are either methylated or unmethylated); none, or very few CpG dyads are hemi-methylated. Shown are the RCP distributions taken from bootstrap samples, weighing each individual evenly within each group (UK = blue, Bangladesh = orange). The sampled population of double-stranded DNA molecules - and the corresponding methylation states of $\mathrm{CpG}$ dyads - revealed a clear preference for a more stable epigenetic maintenance system in operation at the LHR locus in women with a childhood in Bangladesh, when compared to inferred RCP values for the samples from women with a childhood in London. B) Testing if the bootstrap samples of RCP differences (Bangladesh vs UK childhood) are significantly differnt. The red line is set at 0 . The $p$-value is derived from this as the proportion of samples to the left of 0 (a onetailed test to examine whether Bangladesh RCPs are significantly greater than UK RCP values). Two-tailed $p$-value is the double of that amount. $p=0.026$ (one tailed); $p=0.052$ (two tailed)

\section{Conclusions}

The results of our study support a large body of work demonstrating phenotypic plasticity in response to environments encountered during early life. A childhood in Bangladesh measurably accelerates epigenetic/biological ageing in women, when compared to women of same chronological age (18 -35 yrs) and ethnicity, who were born and brought up in London, UK. The multi tissue epigenetic clock is thought to register the workings of developmental and epigenetic maintenance systems linking these processes with the life course $[20,22]$. Our study is one of the first to test if differences in function of the epigenetic maintenance system can be linked with epigenetic age estimators. The findings indicate that subtle differences in the stability of epigenetic states are indeed associated with biological ageing and opens a new line of investigation.

\section{Methods}

\section{DNA methylation data and establishment of DNAm Age}

Genome-wide cytosine methylation levels were established using the Illumina HumanMethylationEPIC BeadChip Array following isolation of genomic DNA from buccal cells DNA (DNeasy Blood \& Tissue Kit (Qiagen). Multidimensional scaling (MDS) plots 
179 indicated that no significant batch effects were skewing the MethylationEPIC BeadChip data

180 sets. The data were processed with the Bioconductor/minfi package. CpG probes associated

181 with known SNPs were removed, as were those with a detection probability of $<0.01$. Probes

182 on both $X$ and $Y$ chromosomes were retained. Methylation beta values (0-1) were

183 normalized by SWAN. The methylation data set (GSE133355 study) is accessible on the

184 Gene Expression Omnibus (GEO) data platform at:

185 https://www.ncbi.nlm.nih.gov/geo/query/acc.cgi?acc=GSE133355

\section{Determination of DNAm Age and age acceleration}

187 A file with the beta values obtained from the Illumina HumanMethylationEPIC BeadChip

188 Array work (see above) was used to establish the epigenetic age (DNAm age and

189 AgeAccelerationResiduals) with Horvath's method [22]. The underlying algorithms are

190 available through the online DNA methylation calculator (http://dnamage.genetics.ucla.edu/).

192 Generation of bisulfite hairpin data / methylation states of CpG dyads at the

\section{LHCGR/LHR locus}

194 We have previously described in detail the concept and procedure of generating

195 authenticated, non-redundant double-stranded DNA methylation data $[19,29,30]$. In brief,

196 genomic sequence information surrounding the $L H R$ clock-CpG site [one of the $353 \mathrm{CpG}$

197 sites contributing to Horvath's clock [22]; Illumina cluster ID cg12351433 / chr2:48982957-

19848982957 / UCSC Genome Browser (GRCh37/hg19)] was used to identify suitable

199 restriction recognition sites to generate 3', or 5'-overhangs, respectively, for the ligation of

200 UMI-barcoded hairpin linkers. Specifically, restriction enzymes Styl or BstXI (New England

201 Biolabs) were used. Combinations of the following primers were used to amplify hairpin-

202 linked, bisulfite converted DNA:

203 bsLHR-R1 5'-RCAAATCAAAACAAAACAAACTC-3';

204 bsLHR-R2 5'-CACTAAACACTATCRCAAATCAAAAC-3';

205 bsLHR-F1 5'-TAGTAGGAAGGAGGTTATTGG-3';

206 bsLHR-F2 5'-GTAGGTTAAGGTAGAGTAGATTTAG-3';

207 bsLHR-F3 5'-GAATTGGGTTTTTGCGGTTTGTTAG-3'.

208 Further information of the hairpin-concept and of the barcoded and batch-stamped hairpin

209 linkers (Eurofins Genomics) are provided in Additional file 1.

211 Processing of the sequencing data: Fold is a web application for the analysis of the output

212 of hairpin-bisulphite sequencing data. Specifically, the programme reconstructs, visualises, 
213 and generates statistics on the double-stranded CpG methylation patterns of the original

214 cohort of DNA molecules. This is achieved by first 'realigning' the top and bottom strand of

215 the molecule about the hairpin, in which the programme attempts to manage 'PCR slippage',

216 and other sequencing errors. Then algorithm then identifies and categorises CpG dyads,

217 which is possible due to the previous bisulphite conversion of unmethylated cytosine to

218 uracil (and so recognised as tyrosine when sequenced). For example, fully methylated

219 dyads are those regions in where the reconstructed top strand is C-G and the bottom is G-C.

220 Similarly, fully unmethylated dyads are those where the top is T-G and the bottom is G-T. In

221 addition, the programme calculates a metric: 'Ratio of Concordance Principle' which

222 quantifies the concordance of methylation between the top and bottom strands of the DNA

223 molecule $(0=$ complete discordance, $1=$ random concordance, inf=complete concordance).

224 This metric represents the preference of the summation of epigenetic mechanisms of the cell

225 to either maintain or obscure methylation patterns of the DNA in the cells at the time the

226 sample was taken. The functions of Fold was written in $\mathrm{R}$ and the web application is written

227 in PHP. The live web application can be found at http://www.gregoryleeman.com/fold, and

228 the repository can be found at https://github.com/gregoryleeman/fold.

229

230 Analysis and comparison of RCPs at the LHCGR/LHR locus

231 RCP values are based on double-stranded DNA methylation data derived from sequences of

232 individual hairpin bisulfite PCRs products. RCP analyses were done following the

233 procedures described in [28] with the small addition of bootstrapping individuals within each

234 population. The additional step in the procedure helps to address the possibility of uneven

235 sampling from a larger population. The analysis procedures in brief are described below.

236 Each population RCP distribution was drawn through hierarchical bootstrap sampling. For

237 each of 20,000 bootstrap samples, individuals in each population were sampled with

238 replacement, and double stranded DNA sequences of each of the sampled individuals were

239 in turn sampled with replacement. Dyad counts were then normalised such that each

240 individual had the same number of dyads. The normalised dyad counts were then summed,

241 corrected for failed bisulfite conversions (rate of 0.0039 , measured empirically) and

242 inappropriate conversions (rate of 0.017, estimated as described in [31] [Genereux et al.,

243 2008]), and used to compute the RCP value. A bootstrap sample of the RCP difference was

244 computed by taking the difference of the RCP values sampled for the two populations.

246 For one-tailed comparison tests, with which we examine directional differences, we

247 determined the $p$-value as the proportion of bootstrap-difference samples to the left of 0 . For 
248 two-tailed tests, with which we can detect differences in any direction, we determined the p-

249 value as twice the smaller proportion of the bootstrap difference samples on either side of 0.

\section{Availability of data and materials}

252 The datasets generated and/or analysed during the current study are available in the Gene

253 Expression Omnibus (GEO) data platform

254 https://www.ncbi.nlm.nih.gov/geo/query/acc.cgi?acc=GSE133355

255 All data generated or analysed during this study are included in this published article and its supplementary information file.

\section{Competing interests}

The authors declare that they have no competing interests.

\section{Funding}

262 This research was supported by the Biotechnology and Biological Science Research Council

263 (BBSRC) and the Economic and Social Research Council (ESRC) grant ES/N000471/1(to

264 GB, PM and RS).

\section{Authors' contributions}

267 RS: Conceptualisation, Funding acquisition, Experimental work, Analysis, Resources,

268 Supervision, Data curation, Project administration, Writing - original draft, Writing - review \& 269 editing.

270 MC: Analysis, review \& editing

271 GL: Analysis, Coding

272 RDE: Analysis, Data curation

273 KB: Experimental work, Resources

274 PM: Funding acquisition, Project administration, Writing - review \& editing.

275 GRB: Conceptualisation, Funding acquisition, Project administration, Writing - review \& 276 editing.

\section{Acknowledgements}

279 We thank Kamila Derecka for technical support, lan C. W. Hardy for statistical advice and

280 Steve Horvath for information on DNAm age analysis. 


\section{References}

284 1. Day FR, Ruth KS, Thompson DJ, Lunetta KL, Pervjakova N, Chasman DI, et al. Largescale genomic analyses link reproductive aging to hypothalamic signaling, breast cancer susceptibility and BRCA1-mediated DNA repair. Nat Genet. Nature Publishing Group; 2015;47:1294-303.

2. Zeng J, De Vlaming R, Wu Y, Robinson MR, Lloyd-Jones LR, Yengo L, et al. Signatures of negative selection in the genetic architecture of human complex traits. Nat Genet. Nature Publishing Group; 2018;50:746-53.

3. Fernández-Rhodes L, Malinowski JR, Wang Y, Tao R, Pankratz N, Jeff JM, et al. The genetic underpinnings of variation in ages at menarche and natural menopause among women from the multi-ethnic Population Architecture using Genomics and Epidemiology (PAGE) Study: A trans-ethnic meta-analysis. Thameem F, editor. PLoS One. Public Library of Science; 2018;13:e0200486.

4. Horikoshi M, Day FR, Akiyama M, Hirata M, Kamatani Y, Matsuda K, et al. Elucidating the genetic architecture of reproductive ageing in the Japanese population. Nat Commun. Nature Publishing Group; 2018;9:1-9.

299 5. Carty CL, Spencer KL, Setiawan VW, Fernandez-Rhodes L, Malinowski J, Buyske S, et

300 al. Replication of genetic loci for ages at menarche and menopause in the multi-ethnic

301 Population Architecture using Genomics and Epidemiology (PAGE) study. Hum Reprod.

302 Oxford University Press; 2013;28:1695-706.

303 6. Parent AS, Teilmann G, Juul A, Skakkebaek NE, Toppari J, Bourguignon JP. The Timing

304 of Normal Puberty and the Age Limits of Sexual Precocity: Variations around the World,

305 Secular Trends, and Changes after Migration. Endocr. Rev. Endocr Rev; 2003. p. 668-93.

306 7. Bar-Sadeh B, Rudnizky S, Pnueli L, Bentley GR, Stöger R, Kaplan A, et al. Unravelling

307 the role of epigenetics in reproductive adaptations to early-life environment. Nat. Rev.

308 Endocrinol. Nature Research; 2020. p. 519-33.

309 8. Magid KS, Uddin Ahamed F, Lawson DW, Chatterton RT, Bentley GR. Effects of adult

310 migration on male salivary testosterone. Am J Hum Biol. 2006;18:262.

311 9. Begum K, Muttukrishna S, Sievert L, Sharmeen T, Murphy L, Chowdhury O, et al.

312 Ethnicity or environment: Effects of migration on ovarian reserve among Bangladeshi

313 women in the UK. Fertil Steril. 2015; under revi.

314 10. Nunez-De La Mora A, Bentley GR, Choudhury OA, Napolitano DA, Chatterton RT. The

315 impact of developmental conditions on adult salivary estradiol levels: why this differs from

316 progesterone? Am J Hum Biol. 2007/10/25. 2008;20:2-14.

317 11. Houghton LC, Cooper GD, Booth M, Chowdhury OA, Troisi R, Ziegler RG, et al. 
318 Childhood environment influences adrenarcheal timing among first-generation Bangladeshi

319 migrant girls to the UK. Sear R, editor. PLoS One. 2014/10/14. 2014;9:e109200.

320 12. Perry JRB, Murray A, Day FR, Ong KK. Molecular insights into the aetiology of female

321 reproductive ageing. Nat. Rev. Endocrinol. Nature Publishing Group; 2015. p. 725-34.

322 13. Núñez-de la Mora A, Chatterton RT, Choudhury OA, Napolitano DA, Bentley GR,

323 Nunez-de la Mora A, et al. Childhood conditions influence adult progesterone levels. Fisk

324 NM, editor. PLoS Med. 2007/05/17. 2007;4:e167.

325 14. Siddique AK, Baqui AH, Eusof A, Zaman K. 1988 floods in Bangladesh: pattern of illness

326 and causes of death. J Diarrhoeal Dis Res. 1991;9:310-4.

327 15. Murphy L, Sievert L, Begum K, Sharmeen T, Puleo E, Chowdhury O, et al. Life course

328 effects on age at menopause among Bangladeshi sedentees and migrants to the UK. Am $\mathrm{J}$

329 Hum Biol. 2012/11/24. 2013;25:83-93.

330 16. Bar-Sadeh B, Pnueli L, Begum K, Leeman G, Emes RD, Stöger R, et al. Early-life

331 environment programs reproductive strategies through epigenetic regulation of SRD5A1 1.

332 bioRxiv. Cold Spring Harbor Laboratory; 2020;2020.09.16.299560.

333 17. Zhu J, Adli M, Zou JY, Verstappen G, Coyne M, Zhang X, et al. Genome-wide Chromatin

334 State Transitions Associated with Developmental and Environmental Cues. Cell.

335 2013;152:642-54.

336 18. Jaenisch R, Bird A. Epigenetic regulation of gene expression: how the genome

337 integrates intrinsic and environmental signals. Nat Genet. 2003;33 Suppl:245-54.

338 19. Laird CD, Pleasant ND, Clark AD, Sneeden JL, Hassan KMA, Manley NC, et al. Hairpin-

339 bisulfite PCR: Assessing epigenetic methylation patterns on complementary strands of

340 individual DNA molecules. Proc Natl Acad Sci U S A. National Academy of Sciences;

$341 \quad 2004 ; 101: 204-9$.

342 20. Horvath S, Raj K. DNA methylation-based biomarkers and the epigenetic clock theory of 343 ageing. Nat Rev Genet. Nature Publishing Group; 2018;19:371-84.

344 21. Khan SS, Singer BD, Vaughan DE. Molecular and physiological manifestations and

345 measurement of aging in humans. Aging Cell. Blackwell Publishing Ltd; 2017;16:624-33.

346 22. Horvath S. DNA methylation age of human tissues and cell types. Genome Biol.

347 2013/10/22. BioMed Central Ltd; 2013;14:R115.

348 23. Dhingra R, Nwanaji-Enwerem JC, Samet M, Ward-Caviness CK. DNA Methylation

349 Age-Environmental Influences, Health Impacts, and Its Role in Environmental

350 Epidemiology. Curr. Environ. Heal. reports. Springer; 2018. p. 317-27.

351 24. Quach A, Levine ME, Tanaka T, Lu AT, Chen BH, Ferrucci L, et al. Epigenetic clock

352 analysis of diet, exercise, education, and lifestyle factors. Aging (Albany NY). 2017;9:419- 
35346.

354 25. Austin MK, Chen E, Ross KM, McEwen LM, Maclsaac JL, Kobor MS, et al. Early-life

355 socioeconomic disadvantage, not current, predicts accelerated epigenetic aging of

356 monocytes. Psychoneuroendocrinology. 2018;97:131-4.

357 26. Levine ME, Lu AT, Quach A, Chen BH, Assimes TL, Bandinelli S, et al. An epigenetic

358 biomarker of aging for lifespan and healthspan. Aging (Albany NY). 2018;10:573-91.

359 27. Editorial. Molecular test of age highlights difficult questions. 2018;561.

360 28. Choi M, Genereux DP, Goodson J, Al-Azzawi H, Allain SQ, Simon N, et al. Epigenetic

361 memory via concordant DNA methylation is inversely correlated to developmental potential

362 of mammalian cells. Barsh GS, editor. PLOS Genet. 2017;13:e1007060.

363 29. Miner BE, Stöger RJ, Burden AF, Laird CD, Hansen RS. Molecular barcodes detect

364 redundancy and contamination in hairpin-bisulfite PCR. Nucleic Acids Res. 2004;32.

365 30. Stöger R. Hairpin-Bisulfite PCR. Methods Mol Biol. NLM (Medline); 2021;2198:287-99.

366 31. Genereux DP, Johnson WC, Burden AF, Stöger R, Laird CD. Errors in the bisulfite

367 conversion of DNA: modulating inappropriate- and failed-conversion frequencies. Nucleic

368 Acids Res. 2008/11/06. Oxford University Press; 2008;36:e150.

369

370 
bioRxiv preprint doi: https://doi.org/10.1101/2020.09 19.304808; this version posted September 20, 2020. The copyright holder for this preprint (which was not certified by peer review) is the author/funder, who has granted bioRxiv a license to display the preprint in perpetuity. It is made available under aCC-BY-NC 4.0 International license.

\section{Additional file 1: Chronological age vs DNAm Age}

Estimates of DNA methylation age (DNAm Age)

The online calculator ( https://dnamage.genetics.ucla.edu/ ) was used to generate estimates of DNAm Age, AgeAccelerationDiff (= DNAmAge-Age), and AgeAccelerationResidual (= the recommended age acceleration measure based on Horvath's linear regression model [Horvath S (2013) DNA methylation age of human tissues and cell types. Genome Biol 14(10):R115 PMID: 24138928].

\begin{tabular}{|c|c|c|c|c|c|c|}
\hline id & Sample ID & $\begin{array}{l}\text { Childhood } \\
\text { location }\end{array}$ & $\begin{array}{c}\text { Age at time } \\
\text { of sample } \\
\text { collection }\end{array}$ & DNAmAge & $\begin{array}{c}\text { AgeAcceleration } \\
\text { Diff }\end{array}$ & $\begin{array}{c}\text { AgeAcceleration } \\
\text { Residual }\end{array}$ \\
\hline 1 & X201247480032_R01C01 & uk & 22 & 30.4 & 8.4 & 7.2 \\
\hline 5 & X201247480032_R04C01 & uk & 25 & 29.0 & 4.0 & 2.4 \\
\hline 8 & X201247480032_R07C01 & uk & 27 & 27.9 & 0.9 & -1.1 \\
\hline 14 & X201247480031_R03C01 & uk & 31 & 30.9 & -0.1 & -2.6 \\
\hline 15 & X201247480031_R04C01 & uk & 33 & 29.1 & -3.9 & -6.6 \\
\hline 22 & X201247480036_R03C01 & uk & 35 & 29.3 & -5.7 & -8.7 \\
\hline 23 & X201247480036_R04C01 & uk & 26 & 24.8 & -1.2 & -3.0 \\
\hline 24 & X201247480036_R05C01 & uk & 27 & 20.4 & -6.6 & -8.6 \\
\hline 25 & X201247480036_R06C01 & uk & 25 & 15.0 & -10.0 & -11.6 \\
\hline 30 & X201247480034_R03C01 & uk & 21 & 22.2 & 1.2 & 0.1 \\
\hline 31 & X201247480034_R04C01 & uk & 26 & 22.7 & -3.3 & -5.1 \\
\hline 2 & X201247480032_R02C01 & bangladesh & 34 & 37.4 & 3.4 & 0.5 \\
\hline 4 & X201247480032_R03C01 & bangladesh & 32 & 50.6 & 18.6 & 16.0 \\
\hline 12 & X201247480031_R01C01 & bangladesh & 35 & 41.3 & 6.3 & 3.2 \\
\hline 13 & X201247480031_R02C01 & bangladesh & 21 & 27.0 & 6.0 & 4.9 \\
\hline 16 & X201247480031_R05C01 & bangladesh & 33 & 44.2 & 11.2 & 8.4 \\
\hline 17 & X201247480031_R06C01 & bangladesh & 28 & 41.5 & 13.5 & 11.4 \\
\hline 18 & X201247480031_R07C01 & bangladesh & 35 & 31.2 & -3.8 & -6.9 \\
\hline 19 & X201247480031_R08C01 & bangladesh & 29 & 25.6 & -3.4 & -5.6 \\
\hline 20 & X201247480036_R01C01 & bangladesh & 32 & 35.9 & 3.9 & 1.3 \\
\hline 21 & X201247480036_R02C01 & bangladesh & 28 & 24.8 & -3.2 & -5.3 \\
\hline 26 & X201247480036_R07C01 & bangladesh & 32 & 37.9 & 5.9 & 3.3 \\
\hline 27 & X201247480036_R08C01 & bangladesh & 35 & 38.1 & 3.1 & 0.0 \\
\hline 28 & X201247480034_R01C01 & bangladesh & 34 & 40.8 & 6.8 & 3.8 \\
\hline 32 & X201247480034_R05C01 & bangladesh & 28 & 32.5 & 4.5 & 2.4 \\
\hline 36 & X201247480034_R07C01 & bangladesh & 22 & 25.2 & 3.2 & 1.9 \\
\hline
\end{tabular}


Prism GraphPad 8 analysis / Chronological age vs DNAm Age:

390 The slopes of the regression lines between the 'UK' group $(n=11)$ and the 'Bangladesh' group $(n=15)$ are not significantly different $(F=1.136$; $D F n=1, D F d=22 p=0.29)$. Therefore, a single slope for data of the entire cohort can be established: the pooled slope equals 0.8128 (Additional Fig 1a). However,

\section{Additional Fig 1a}

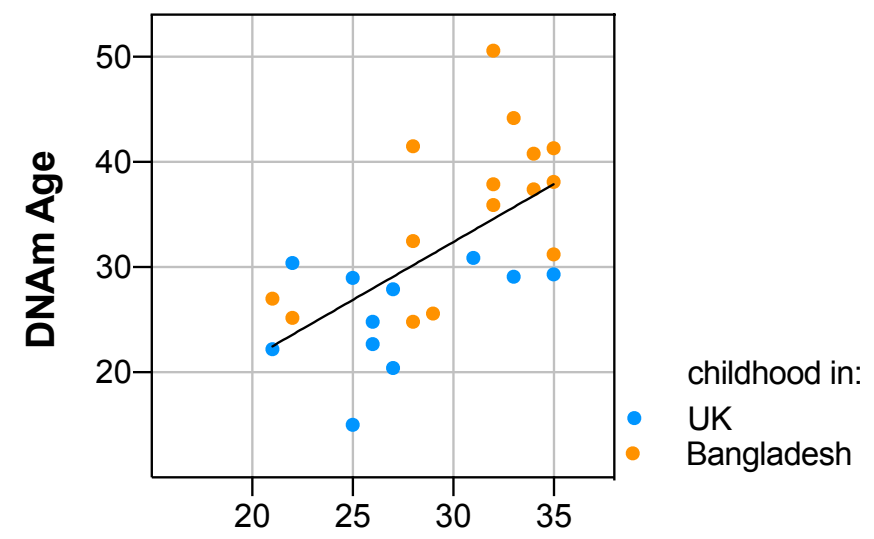

Chronological Age

Additional Fig 1a: Plot of predicted methylation age (Horvath clock) against chronological age. The scatter plot shows DNA methylation age vs. chronological age vs. and the line in which DNA methylation age was regressed on chronological age using both, the 'UK' and the 'Bangladesh' data sets. 'UK' = Bangladeshi women who grew up in London, UK (blue); 'Bangladesh' = Bangladeshi women who grew up in Sylhet, Bangladesh. Each data point represents an individual, with the colour indicating the corresponding dataset.

402

Genstat analysis / Chronological age vs DNAm Age:

404 Genstat analysis of covariance yielded similar results to those obtained by Prism GraphPad 8 analysis, in that Bangladeshi women with a childhood in the UK and Bangladeshi women with a childhood in Bangladesh are affected by chronological age the same way - the two slopes are the same based on a minimal adequate mode (Additional Fig 1b). Parameters needed to reconstruct the lines are indicated in yellow:

\section{Estimates of parameters}

$\begin{array}{lllll}\text { Parameter } & \text { estimate } & \text { s.e. } & \mathrm{t}(23) & \mathrm{t} \text { pr. } \\ \text { Constant } & 10.78 & 8.35 & 1.29 & 0.209 \\ \text { Country UK } & -7.19 & 2.49 & -2.89 & 0.008 \\ \text { chronological_age } & 0.813 & 0.269 & 3.02 & 0.00\end{array}$

Parameters for factors are differences compared with the reference level:

$$
\begin{array}{ll}
\text { Factor } & \text { Reference level } \\
\text { Country } & \text { Bangladesh }
\end{array}
$$

\section{Accumulated analysis of variance}

Change

+ chronological_age

S.S.

+ chronological_age.Country

Residual

38.32

- chronological_age.Country

- Country

+ Country

- chronological_age

+ chronological_age

Total
741.94

$-38.32$

$-282.95$

282.95

$-309.57$

309.57

25

1723.29 m.s. v.r. F pr.

$660.09 \quad 19.57<.001$

$\begin{array}{lll}282.95 & 8.39 & 0.008\end{array}$

$\begin{array}{lll}38.32 & 1.14 & 0.298\end{array}$

33.72

38.32 1.140 .298 interaction not significant

$282.95 \quad 8.390 .008$ country significant

$282.95 \quad 8.390 .008$ country put back into model

$309.57 \quad 9.180 .006$ age significant

$309.57 \quad 9.180 .006$ age put back into model, so that the final

432 
Additional Fig 1b: The minimal adequate model (Genstat analysis):

434

\section{Additional Fig $1 \mathrm{~b}$}

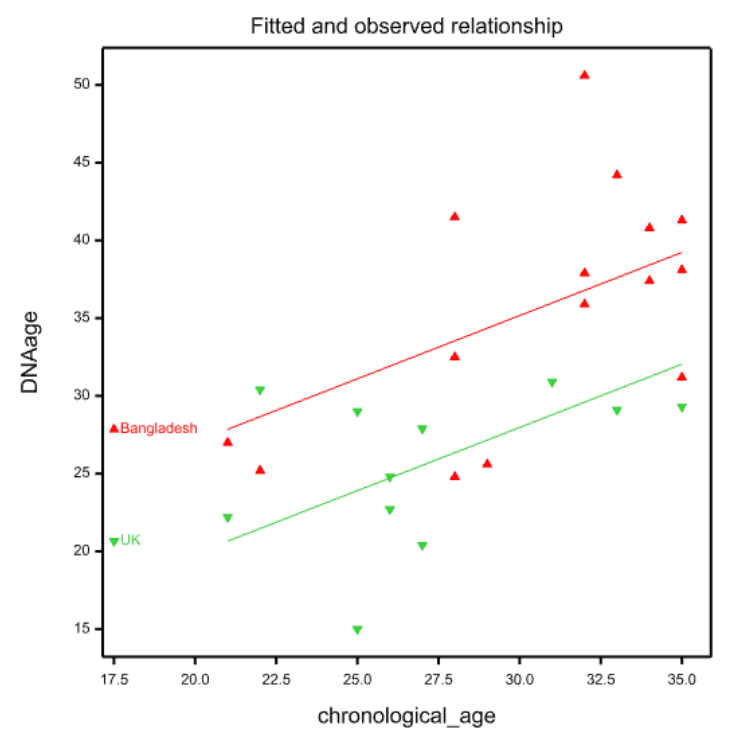

DNA sequence surrounding the LHR-clock CpG site analysed by hairpin bisulfite PCR The CpG site [clock CpG] at the Luteinizing Hormone/Choriogonadotropin Receptor (LHCGR/LHR) locus, which contributes to 'Horvath's clock' (Horvath, 2013) was PCR-amplified following hairpin linker-ligation and sodium bisulfite conversion. The hairpin PCR products also captured methylation information of flanking CpGs (highlighted in red): four CpGs with the Styl-hairpin linker approach and eight $\mathrm{CpGs}$ with the BstXI-hairpin linker approach, respectively: 
bioRxiv preprint doi: https://doi.org/10.1101/2020.09.19.304808; this version posted September 20, 2020. The copyright holder for this preprint (which was not certified by peer review) is the author/funder, who has granted bioRxiv a license to display the preprint in perpetuity. It is made available under aCC-BY-NC 4.0 International license.

BstXI- and Styl-hairpin linkers used in this study

448

\begin{tabular}{|l|l|l|l|}
\hline Name: & Sequence: & individual & converted \\
\hline hLHR-hp-III & ACAGTGCADDDDDDDDTGCACTGTtgtc & $\# 12$ & ATAGTGTADDDDDDDDTGTATTGTtgtT \\
\hline hLHR-hp-1 & ACATGGCADDDDDDDDTGCCATGTtgtc & $\# 16$ & ATATGGTADDDDDDDDTGTTATGTtgtT \\
\hline hLHR-hp-2 & ATCGTGCADDDDDDDDTGCACGATtgtc & $\# 17$ & ATTGTGTADDDDDDDDTGTATGATtgtT \\
\hline hLHR-hp-3 & AAGGTGCADDDDDDDDTGCACCTTtgtc & $\# 19$ & AAGGTGTADDDDDDDDTGTATTTTtgtT \\
\hline hLHR-hp-4 & AACCTGCADDDDDDDDTGCAGGTTtgtc & $\# 22$ & AATTTGTADDDDDDDDTGTAGGTTtgtT \\
\hline hLHR-hp-5 & TAGCACGTDDDDDDDDACGTGCTAtgtc & $\# 13$ & TAGTATGTDDDDDDDDATGTGTTAtgtT \\
\hline hLHR-hp-6 & TTACACGTDDDDDDDDACGTGTAAtgtc & $\# 15$ & TTATATGTDDDDDDDDATGTGTAAtgtT \\
\hline hLHR-hp-7 & TTCCACGTDDDDDDDDACGTGGAAtgtc & $\# 23$ & TTTTATGTDDDDDDDDATGTGGAAtgtT \\
\hline hLHR-hp-8 & TTTCACGTDDDDDDDDACGTGAAAtgtc & $\# 29$ & TTTTATGTDDDDDDDDATGTGAAAtgtT \\
\hline hLHR-hp-9 & TTGAACGTDDDDDDDDACGTTCAAtgtc & $\# 30$ & TTGAATGTDDDDDDDDATGTTTAAtgtT \\
\hline hLHR-hp-10 & TTGTACGTDDDDDDDDACGTACAAtgtc & $\# 31$ & TTGTATGTDDDDDDDDATGTATAAtgtT \\
\hline Styl & & & \\
\hline hLHR-hp-11 & caagACATGGCADDDDDDDDTGCCATGT & $\# 5 / 6$ & taagATATGGTADDDDDDDDTGTTATGT \\
\hline hLHR-hp-12 & caagATCGTGCADDDDDDDDTGCACGAT & $\# 7$ & taagATTGTGTADDDDDDDDTGTATGAT \\
\hline hLHR-hp-13 & caagAAGGTGCADDDDDDDDTGCACCTT & $\# 8$ & taagAAGGTGTADDDDDDDDTGTATTTT \\
\hline hLHR-hp-14 & caagAACCTGCADDDDDDDDTGCAGGTT & $\# 10$ & taagAATTTGTADDDDDDDDTGTAGGTT \\
\hline hLHR-hp-15 & caagTAGCACGTDDDDDDDDACGTGCTA & $\# 25$ & taagTAGTATGTDDDDDDDDATGTGTTA \\
\hline hLHR-hp-16 & caagTTACACGTDDDDDDDDACGTGTAA & $\# 16$ & taagTTATATGTDDDDDDDDATGTGTAA \\
\hline hLHR-hp-17 & caagTTCCACGTDDDDDDDDACGTGGAA & $\# 17$ & taagTTTTATGTDDDDDDDDATGTGGAA \\
\hline hLHR-hp-18 & caagTTTCACGTDDDDDDDDACGTGAAA & $\# 18 / \# 27$ & taagTTTTATGTDDDDDDDDATGTGAAA \\
\hline hLHR-hp-19 & caagTTGAACGTDDDDDDDDACGTTCAA & $\# 20 / \# 28$ & taagTTGAATGTDDDDDDDDATGTTTAA \\
\hline hLHR-hp-20 & caagTTGTACGTDDDDDDDDACGTACAA & $\# 36 / \# 32$ & taagTTGTATGTDDDDDDDDATGTATAA \\
\hline
\end{tabular}

Double-stranded methylation data of individual DNA molecules derived from buccal cells The data shown on page 5 are processed, in that the methylation status of matching $\mathrm{CpG}$ sites of the top- and bottom strands (CpG dyads) are indicated as methylated $(=1)$, or unmethylated $(=0)$. Information of individual, double-stranded DNA molecules is displayed as follows:

456

457

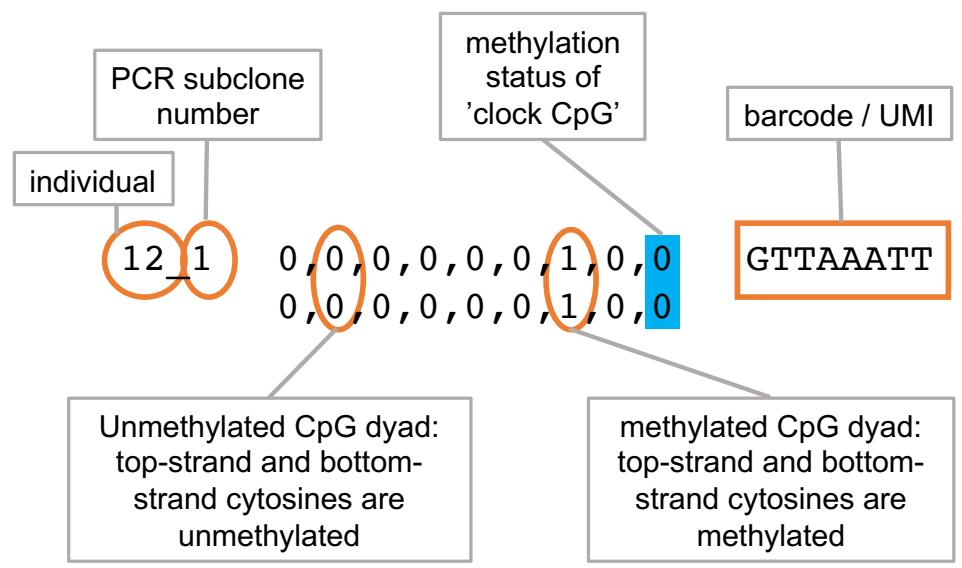


bioRxiv preprint doi: https://doi.org/10.1101/2020.09.19.304808; this version posted September 20, 2020. The copyright holder for this preprint (which was not certified by peer review) is the author/funder, who has granted bioRxiv a license to display the preprint in perpetuity. It is made available under aCC-BY-NC 4.0 International license.

462 Hairpin methylation data / Bangladesh-childhood

GTTAAATT

GTATTATT

TGGTTTTA

GGTTGAGG

ATTTGTTG

TAGGAGTG

GGTTTGAA

GGTGTGTT

AGATGTAA

TTGGAGGG

ATTTAGTT

TGTAAAGA

TGTTTTTT

ATTTTAGG

TTGGATTT

TTGAAAGG

GGGTTAAG

AAGAGAGT

TTGTTATA

TAAATGTA

TTAGATGG

TGATATAA

GGGTTGGG

GATTGATA

GGGTTAAG

TAGTATAT

AAAAATAA

ATAGGAAG

TGGGATGA

TATGTTTG

GAGAAATG

TTTATTGT

TTTGTAGA

ATGTTAGT

ATGAGGGG

GTTTGAAG

GTGAATAT

TAGGGAAT 
bioRxiv preprint doi: https://doi.org/10.1101/2020.09.19.304808; this version posted September 20, 2020. The copyright holder for this preprint (which was not certified by peer review) is the author/funder, who has granted bioRxiv a license to display the preprint in perpetuity. It is made available under aCC-BY-NC 4.0 International license.

GAAATAGT

GTGTGTAT

TGATGTGA

ATAGTAAT

ATATGTTC

AGTTGAGG

TTTAAAAA

GATAATTT

GTTGTTGT

TTGTGTAT

TTGGGTAT

АТTТАТTT

GTGGAGGT

TAAGTAGG

AATGTTGT

TTAAGGGT

TTAAAGGT

TAGATTTG

GGGATTTT

AGATTGTG

TTAATAAT

AGAGATGG

GAAGGATA

TAGGTAGG

GGGGATGG

AAATGTGG

GTAGTTTA

ATAAAGAG

GTGAGGAG

GATGGGGT

TATGAGTG

AAAAATTG

ATGAGGAT

GGTGATTG

TGGGATAA

GGATGTGA

TAAGGGGG

GGAGAAGT 
bioRxiv preprint doi: https://doi.org/10.1101/2020.09.19.304808; this version posted September 20, 2020. The copyright holder for this preprint (which was not certified by peer review) is the author/funder, who has granted bioRxiv a license to display the preprint in perpetuity. It is made available under aCC-BY-NC 4.0 International license.

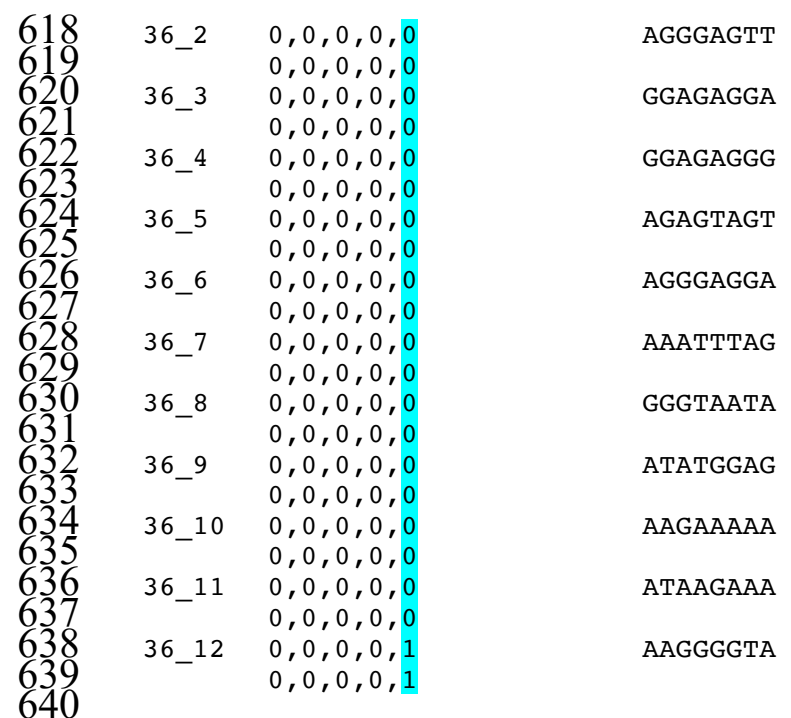

\section{Hairpin methylation data / Bangladesh-childhood}

GGATGATA

$1,1,1,0,1$

5_5 $0,0,0,0,1$

$0,0,0,0,0$

15_1 $0,0,0,0,0,0,0,0,0$

$0,0,0,0,0,0,0,0,0$

15_2 $\quad 0,0,0,0,0,0,0,0,0$

$0,0,0,0,0,0,0,0,0$
$0,0,0,0,0,0,0,0,0$

15_3 $0,0,0,0,0,0,0,0,0$

$0,0,0,0,0,0,0,0,0$

GATAGTTG

$15 \_4 \quad 0,0,0,0,0,0,1,0,1$

$0,0,0,0,0,1,1,0,1$

$15 \_0,0,0,0,0,0,1,0,0$

GTTTAGGT

TGGGGTGA

ATATGAGA

ATGGGAGA

GATTGTAA

ATAGGGAA

TTGAAGAT

$156 \quad 0,0,0,0,0,0,0,0,0$

TGGTTAAA

TAAAGAAA

$157 \quad 0,0,0,0,0,0,0,0,0$

TATтTTTT

$0,0,0,0,0,0,0,0,0$
$\quad 0,0,0,0,0,0,0,0,0$

TGTATGTA

15_9 $0,0,0,0,0,0,0,0,0$ $0,0,0,0,0,0,0,0,0$

AAGTAAAG

$0,0,1,0,0,0,0,0,0$

$1511 \quad 1,1,0,0,0,0,1,0,0$

AAAATTGA

$15 \_12 \quad 0,0,0,0,0,0,0,0,0$

GTGTGGGG

$0,0,0,0,0,0,0,0,0$

15_13 $0,1,0,0,0,0,0,0,0$ $0,1,0,0,0,0,0,0,0$

TAGTTGGA

15_14 $1,1,1,1,1,0,0,0,1$

AATGTAAA

$15 \_15 \quad 0,0,0,0,0,0,0,0,0$

TTGGTAGG

$0,0,0,0,0,0,0,0,0$

GTATTATG

$0,0,0,0,0,0,1,0,1$

ATAAGGGA

$30 \_1 \quad 0,0,0,0,0,0,0,0,0$ 
bioRxiv preprint doi: https://doi.org/10.1101/2020.09.19.304808; this version posted September 20, 2020. The copyright holder for this preprint (which was not certified by peer review) is the author/funder, who has granted bioRxiv a license to display the preprint in perpetuity. It is made available under aCC-BY-NC 4.0 International license.

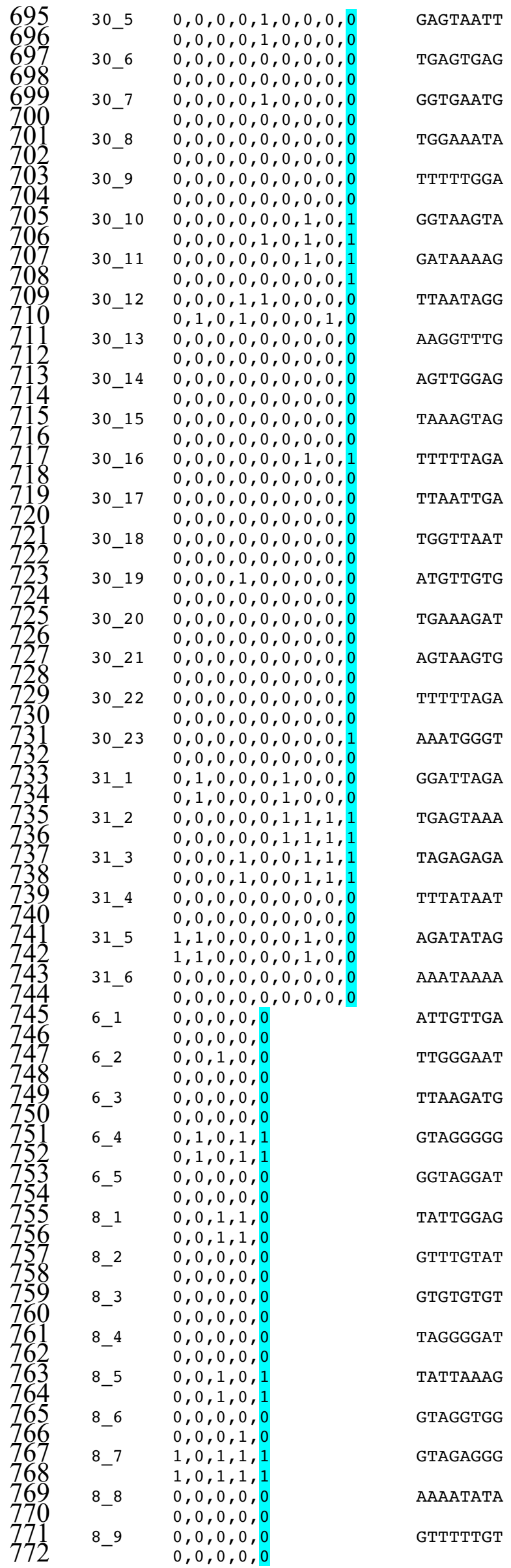


bioRxiv preprint doi: https://doi.org/10.1101/2020.09.19.304808; this version posted September 20, 2020. The copyright holder for this preprint (which was not certified by peer review) is the author/funder, who has granted bioRxiv a license to display the preprint in perpetuity. It is made available under aCC-BY-NC 4.0 International license.

\begin{tabular}{|c|c|c|}
\hline 8_10 & $0,0,0,0,0$ & GAGGTTAT \\
\hline 8_11 & $\begin{array}{l}0,0,0,0,1 \\
0,0,0,0,0 \\
0,0,0,0,0\end{array}$ & TGTAGGAA \\
\hline 8_12 & $\begin{array}{l}0,0,1,1,1 \\
0,0,1,1,1\end{array}$ & AATTTGTT \\
\hline 8_13 & $\begin{array}{l}0,0,0,0,0 \\
0,0,0,0,0\end{array}$ & АAGTTTAT \\
\hline 8_14 & $\begin{array}{l}0,0,0,0,0 \\
0,0,0,0,0\end{array}$ & TGGATTTG \\
\hline 8_15 & $\begin{array}{l}0,0,0,0,0 \\
0,0,1,1,1\end{array}$ & TATTAGGT \\
\hline 8_16 & $\begin{array}{l}0,0,0,0,0 \\
0,0,0,0,0\end{array}$ & TATTGGAT \\
\hline 8_17 & $\begin{array}{l}0,0,0,0,0 \\
0,0,0,0,0\end{array}$ & AATTGGGT \\
\hline 8_18 & $\begin{array}{l}0,0,0,0,0 \\
0,0,0,0,0\end{array}$ & TGTTGTAA \\
\hline 8_19 & $\begin{array}{l}0,0,1,0,1 \\
0,0,1,0,1\end{array}$ & AGGATATA \\
\hline 8_20 & $\begin{array}{l}0,0,1,0,0 \\
0,0,1,0,0\end{array}$ & AGTTAGGT \\
\hline 8_21 & $\begin{array}{l}0,0,0,0,0 \\
0,0,0,0,0\end{array}$ & TTAGTAAG \\
\hline 8_22 & $\begin{array}{l}0,0,1,1,1 \\
0,0,1,1,1\end{array}$ & GAATTTGT \\
\hline 8_23 & $\begin{array}{l}0,0,0,0,0 \\
0,0,0,0,0\end{array}$ & GAAATGGA \\
\hline 8_24 & $\begin{array}{l}0,0,0,0,0 \\
0,0,0,0,0\end{array}$ & GTTGTTAA \\
\hline $8 \_25$ & $\begin{array}{l}1,0,1,1,1 \\
0,0,0,0,0\end{array}$ & TTTTGGGT \\
\hline 8_26 & $\begin{array}{l}0,0,0,0,0 \\
0,0,0,0,0\end{array}$ & GATAAGGG \\
\hline 8_27 & $\begin{array}{l}0,0,0,0,0 \\
0,0,0,0,0\end{array}$ & GGAAGTTG \\
\hline 8_28 & $\begin{array}{l}0,1,1,1,1 \\
0,1,1,1,1\end{array}$ & AGTAATGT \\
\hline 8_29 & $\begin{array}{l}0,0,0,0,0 \\
0,0,0,0,0\end{array}$ & AAATGGGT \\
\hline 8_30 & $\begin{array}{l}0,0,0,0,0 \\
0,0,0,0,0\end{array}$ & AGTTTGGT \\
\hline 8_31 & $\begin{array}{l}0,0,0,0,0 \\
0,0,0,0,0\end{array}$ & GAGATTTT \\
\hline
\end{tabular}

